The Quarterly Journal of Austrian Economics

Volume 23 | NO. 2 | 171-179 | SuMmer 2020 WWW.QJAE.ORG

\title{
The Disutility of LABor
}

\section{Tate Fegley and Karl-Friedrich Israel*}

JEL Classification: D01, J01, J20, J22

Aвstract: Some Austrian economists have argued that the disutility of labor is a necessary auxiliary empirical assumption to complement otherwise a priori economic theory in order for it to apply to the real world. Without this assumption, it is claimed that individuals will supply the full quantity of labor of which they are physically capable. We argue that the disutility of labor assumption is unnecessary to derive this conclusion, which can instead be derived through standard marginal analysis. Leisure (the state of not engaging in labor) is a necessary complementary good for consuming other goods. As such, leisure's status as a consumer good is a priori true, not an empirical assumption. Furthermore, the concept of disutility of labor is not only unnecessary but also leads to confusion due to its being used in two different ways, and therefore ought to be discarded.

\section{INTRODUCTION}

Drominent economists in the Austrian tradition, including 1 Ludwig von Mises and Murray Rothbard, consider the empirical assumption that labor involves disutility to be necessary to supplement the otherwise a priori analysis of praxeology in order

\footnotetext{
* Tate Fegley (tfegley@gmu.edu) is a postdoctoral associate at the Center for Governance and Markets at the University of Pittsburgh. Karl-Friedrich Israel (israel@ wifa.uni-leipzig.de) is senior researcher at the Institute for Economic Policy at Leipzig University, Germany. The authors would like to thank Ash Navabi, Kristoffer Mousten Hansen, Łukasz Dominiak, and an anonymous referee for their helpful comments.
} 
to develop a theory that is relevant to our world. Without such an assumption, Mises argues, individuals would supply as much labor as they are physically capable of providing:

In a world in which labor is economized only on account of its being available in a quantity insufficient to attain all ends for which it can be used as a means, the supply of labor available would be equal to the whole quantity of labor which all men together are able to expend. In such a world everybody would be eager to work until he had completely exhausted his momentary capacity to work. The time which is not required for recreation and restoration of the capacity to work, used up by previous working, would be entirely devoted to work. $(1998,131)$

However, in our world, as Mises would argue, labor is usually also economized on account of its involving disutility, and therefore individuals will cease to engage in labor even if they are physically capable of providing more. In contrast to Mises's fundamental concept of action, the assumption of disutility of labor is not a necessary prerequisite of praxeological analysis. He explains:

The disutility of labor is not of a categorial and aprioristic character. We can without contradiction think of a world in which labor does not cause uneasiness, and we can depict the state of affairs prevailing in such a world. But the real world is conditioned by the disutility of labor. Only theorems based on the assumption that labor is a source of uneasiness are applicable for the comprehension of what is going on in this world. (Mises 1998, 65)

Similarly, Rothbard $(1957,316)$ states that praxeology contains one fundamental, a priori axiom - the action axiom — and a few subsidiary empirical postulates, including the assumption that leisure is a consumer good. ${ }^{1}$ This could be interpreted as being equivalent to the assumption that labor carries disutility. If leisure were not a consumer good, then labor would not involve disutility, and individuals would not consider forgone leisure a cost. In such a world, they would provide as much labor as physically possible. But is that really true?

We argue that the empirical assumption that labor involves disutility is not necessary in order to derive the implication that

\footnotetext{
${ }^{1}$ Interestingly, Rothbard $(1957,316)$ states that this assumption is unnecessary "for an analysis of Crusoe economics, of barter, and of a monetary economy."
} 
individuals will not choose to supply as much labor as they are physically able, but that such an implication can be derived through standard marginal analysis. Moreover, we will argue that equating the existence of opportunity costs to disutility is inconsistent. In addition to the benefit of making economic theory more parsimonious, we believe our paper clarifies this otherwise confusing concept.

\section{DISUTILITY OF LABOR DEFINED}

Before defining disutility of labor, it is helpful to define what labor is. According to Mises, labor is "the employment of the physiological functions and manifestations of human life as a means" (1998, 131), whereas leisure is the absence of labor. Alternatively, we could define leisure as the employment of the physiological functions and manifestations of human life as an end. This means that leisure is not only the act of "doing nothing," but the use of one's body for consumption, rather than production. This distinction involves a subjective element. The same physical activity could be labor or leisure depending on whether it directly serves the ends of the individual engaged in the activity, or does so only indirectly. To be clear, labor as such is a means. The physical activity undertaken cannot be solely an independent end itself, otherwise it would be considered leisure.

The disutility of labor is the forgone utility of forgone leisure. Leisure, as any other consumer good, is subject to the law of diminishing marginal utility: if only one unit of leisure is available, it is used to satisfy the highest ranked end. If two units of leisure are available the next most highly ranked end will be satisfied as well, and so on. The disutility of labor is the inverse of this process: one unit of time spent laboring will come at the cost of the lowest ranked end that would have been served by time in leisure, the second unit of labor will come at the cost of the second lowest ranked end, and so forth. Thus, labor is subject to increasing marginal disutility (Mises $1998,132) .^{2}$ In other words, the disutility of labor is its opportunity cost in terms of leisure forgone.

\footnotetext{
${ }^{2}$ Mises $(1998,132)$ writes, "We must conclude that the first unit of leisure satisfies a desire more urgently felt than the second one, the second one a more urgent desire than the third one, and so on. Reversing this proposition, we get the statement that the disutility of labor felt by the worker increases in a greater proportion than the amount of labor expended."
} 
It would be simple enough to stop here in terms of defining the disutility of labor, as the given definition is sufficient to accomplish the task of explaining what purely a priori reasoning is accused of being insufficient to explain, i.e., why individuals ever cease to engage in labor. However, there is plenty of confusion surrounding the concept of disutility of labor that must be addressed. Much of this confusion is the result of incorporating psychological elements into the disutility of labor, such that it is these psychological elements that become its defining feature. Indeed, Greaves (1974, 34-35), in his glossary for Human Action, defines the disutility of labor as "the discomfort, uneasiness, inconvenience or pain inherent in human effort. Because of this quality men regard labor as a burden and prefer leisure to toil or labor."

It is not difficult to see why Greaves would define the disutility of labor in such a way, as Mises himself writes,

The expenditure of labor is deemed painful. Not to work is considered a state of affairs more satisfactory than working. Leisure is, other things being equal, preferred to travail. People work only when they value the return of labor higher than the decrease in satisfaction brought about by the curtailment of leisure. To work involves disutility. $(1998,131-32)$

There are a number of passages in Human Action and Socialism in which the way Mises refers to the disutility of labor makes it seem as though it is a psychological phenomenon, an obstacle to be "overcome," rather than merely the opportunity cost of engaging in labor. For example, Mises $(1998,584-85)$ lists a number of reasons why someone might choose to forgo the enjoyment of leisure, such as strength of mind and body, to serve God, and to avoid greater mischief, and states that, in these cases, "the disutility of labor in itself-and not its product—satisfies."

Besides being utterly confusing, as Mises' statement ultimately suggests that "disutility" can generate something like "utility," i.e. that it can satisfy wants, it would imply that the disutility of labor is not the utility of leisure forgone, but the pain, discomfort, or unpleasantness of engaging in labor. Although Mises (1998, 585-89) attempts to distinguish the disutility of labor from the psychological phenomena of the "joy" and "tedium" of labor, in so doing he identifies the disutility of labor with unpleasantness, rather than strictly 
the opportunity cost of forgone leisure. One of the sources from which the joy of labor springs is that, after having completed a task, a worker "enjoys the feeling of having successfully overcome all the toil and trouble involved. He is happy in being rid of something difficult, unpleasant, and painful, in being relieved for a certain time of the disutility of labor" (Mises, 1998, 586). Mises (1981) also writes of labor directly satisfying the human need of "stirring," which is "a physical and mental need." But it only does this to a certain point, beyond which labor becomes toil. ${ }^{3}$

Likewise, Rothbard (2009) includes the disagreeable conditions under which labor is performed as part of what constitutes the disutility of labor:

In some cases, labor itself may be positively disagreeable, not only because of the leisure forgone, but also because of specific conditions attached to the particular labor that the actor finds disagreeable. In these cases, the marginal disutility of labor includes both the disutility due to these conditions and the disutility due to leisure forgone.

Thus, these two conceptions of the disutility of labor-(Conception 1 ) as the forgone utility of leisure and (Conception 2) the unpleasantness, discomfort, or pain involved in laboring-need not be considered mutually exclusive, and the latter can be classified as a subset of the former. That is, if part of the utility derived from leisure is the avoidance of the unpleasantness of labor, then that would be utility forgone when one engages in labor.

\section{WHY THE DISUTILITY OF LABOR ASSUMPTION IS UNNECESSARY}

Conception 2 of the disutility of labor, even though considered by Greaves to be the essence of the concept, is superfluous in terms of doing the work that Mises and Rothbard want the empirical assumption to accomplish. That is, even if labor carried with it no unpleasantness, pain, or discomfort, it would still involve the forgone utility of forgone leisure. Furthermore, Conception 2 also

\footnotetext{
${ }^{3}$ The only graph Mises $(1981,145)$ ever uses in his texts is to illustrate the relationship between the time spent in labor and its direct satisfaction or dissatisfaction.
} 
seems to be the "empirical" part of the "empirical assumption" of disutility of labor that we can imagine being different. Contrary to what Mises and Rothbard argue, we cannot without contradiction conceive of a world in which Conception 1 is false, i.e., a world in which engaging in labor has no opportunity cost. Hence, it is not really an additional assumption that supplements otherwise a priori praxeological theory, but rather an aspect of it that is already implied in the concept or axiom of action. Any specific course of action, be it classified as labor or leisure, has opportunity costs, as the choice of one action presupposes alternatives that must be forgone.

What ought to be apparent by this point in our discussion is the awkwardness of the phrase "disutility of labor," if what is meant by it is the opportunity cost of labor and if one of the purposes of the assumption is to explain why individuals do not engage in all of the labor they are physically capable of performing. It is unclear what is unique about labor in this regard. If, as Rothbard $(1957,316)$ states, the proposition that leisure is a good is so generally true as to be self-evident, why do we not resort to an assumption about the "disutility of leisure" to explain why individuals ever start to labor in the first place? Indeed, why not assume that every action involves "disutility" to explain why people ever stop doing anything?

The reason is that we already have concepts to explain these things: diminishing marginal utility and opportunity cost. The fact that people do not devote themselves fully to labor can also be explained through these concepts. There are diminishing marginal returns to labor: the first unit of time allocated to labor will be to satisfy the highest ranked end, the next unit to the second most highly ranked end, et cetera. Using one's body for labor incurs an opportunity cost-one's body cannot be used to serve other ends one may have. Thus, as individuals engage in further labor, the utility derived from the fruits of their labor diminishes, while the marginal utility of ends forgone remains the same. Eventually, the marginal utility of another unit of labor will be less than the marginal utility of a unit of leisure, and one will cease to labor.

But is that not the work that the assumption that "leisure is a consumer good" is doing, that is, assuming that labor has an opportunity cost? We argue that such an assumption is superfluous, and it is already implied in the definition of labor. Recall that labor is "the 
employment of the physiological functions and manifestations of human life as a means." Thus, people labor so that they can consume. This raises the question, though neither Mises nor Rothbard address it specifically, of what, if any, the relationship between leisure and consumption is. ${ }^{4}$ Only if it is the case that there is no necessary relationship and one can engage in all types of consumption he or she desires without ceasing to labor, could it be possible at all that individuals would supply all the labor of which they are physically capable of providing. Only under such conditions would there be no opportunity cost, in terms of forgone consumption, to engaging in labor. But the action axiom implies that the use of the human body is scarce and one must prioritize among ends. In order to use one's body to enjoy consumer goods, leisure- the employment of the physiological functions and manifestations of human life as an end-is a complementary good. This is why we conclude that a world in which leisure is not a consumer good is inconceivable, unless it is a world in which no consumption takes place, but this raises the question of why anyone would choose to engage in labor in the first place, since the ultimate purpose of labor is consumption.

The reason why people engage in labor is so that they can consume and if they are to consume, they must refrain from labor. Thus, eventually ceasing from labor is already implied in the concept of labor itself, that is, when labor is understood as a means to attain ends, notably some form of consumption. The end is thus not the labor itself, but rather the enjoyment of its ultimate attainment, which precludes labor. If it were the case that individuals never stopped engaging in labor, then the physical acts they are performing can no longer be considered labor (which is a means), but ought to be considered ends in themselves.

Even if it were considered as an end in itself, labor would obviously have utility or value. And yet, it still would have opportunity costs. Hence, even if it were an end in itself, we would at some point stop laboring. The extra assumption of disutility is not required. Nor is it required for labor as a means. In fact, even simply by virtue of

\footnotetext{
${ }^{4}$ Rothbard $(2009,46)$ states, "Leisure is the amount of time not spent in labor, and play may be considered as one of the forms that leisure may take in yielding satisfaction." This implies that there is a mutual exclusivity between labor and at least some types of consumption.
} 
being a means labor should be regarded as having utility instead of disutility. Just like any other means it derives its value from that of the ends it serves to attain.

A world in which labor carried with it no unpleasantness, pain, or discomfort is conceivable without contradiction. But it should be clear why such a world would not be one in which individuals supply all of the labor they are physically capable of performing. Labor would still involve the opportunity cost of various types of consumption forgone. But likewise, any specific type of consumption carries with it the opportunity cost of another type of consumption. Would anybody therefore argue that there is disutility of consumption?

\section{CONCLUSION}

We have attempted to clarify the meaning of the phrase "disutility of labor" and to highlight the confusions its use has caused. It is most often identified with unpleasantness in performing labor (Conception 2), which may affect the supply of labor in various occupations and therefore the respective height of monetary wages, but such a conception is irrelevant in regards to whether individuals will ever cease to labor. If all that is meant by it is that labor has an opportunity cost (Conception 1) - that the use of one's body for labor comes at the cost of not using one's body for consumption-then there is nothing exceptional about human effort compared to any other scarce resource that has alternative uses. Just as for any consumer good or productive factor, there is no need to resort to a concept of "disutility" in order to explain why people stop consuming a good or employing a factor before they have exhausted their full stock. Rather, they consume units of a good and employ productive factors as long as the expected marginal benefits are greater than the marginal costs. The use of their bodies for labor and leisure is subject to the same reasoning.

This has implications for the applied analysis of consumer behavior. An unstated assumption of the idea that people would engage in labor as much as they are physically capable if they did not directly value leisure is that the process of consuming takes place more or less instantaneously. However, just as production takes 
place over time, so does consumption, and just as the time involved in a production process is relevant to its value, the time needed to consume various goods is relevant to consumers' valuation of those goods. Labor supply may be more sensitive to changes in the quality of time-intensive consumer goods than it is to changes in labor productivity or how unpleasant work is. ${ }^{5}$ Appreciating the role time plays in consumer decision-making may lead to a more informed analysis of a variety of observed phenomena, from changes in workforce participation to changes in fertility rates.

\section{REFERENCES}

Becker, Gary S. 1965. "A Theory of the Allocation of Time." Economic Journal 75, no. 299: 493-517.

Greaves, Percy L. 1974. Mises Made Easier: A Glossary for Ludwig von Mises' Human Action. Dobbs Ferry, NY: Free Market Books.

Mises, Ludwig von. 1981. Socialism: An Economic and Sociological Analysis. Indianapolis, Ind.: Liberty Fund.

—. 1998. Human Action: A Treatise on Economics. Scholar's Edition. Auburn, Ala.: Ludwig von Mises Institute.

Rothbard, Murray N. 1957. "In Defense of 'Extreme Apriorism."' Southern Economic Journal 23, no. 3: 314-20.

. 2009. Man, Economy, and State with Power and Market. Scholar's Edition, $2^{\text {nd }}$ ed. Auburn, Ala.: Ludwig von Mises Institute.

${ }^{5}$ See Becker (1965) for a discussion of the allocation of time between earnings-generating and other activities. 